\title{
Optimized Algorithm Analysis of Factors Affecting the Effectiveness of English Teaching under the New Curriculum Concept
}

\author{
Lu Zhang \\ School of English Language and Literature, Xi'an Fanyi University, Xi'an 710105, Shaanxi, China \\ Correspondence should be addressed to Lu Zhang; zl_8583@163.com
}

Received 29 October 2021; Accepted 14 December 2021; Published 24 January 2022

Academic Editor: Punit Gupta

Copyright (c) 2022 Lu Zhang. This is an open access article distributed under the Creative Commons Attribution License, which permits unrestricted use, distribution, and reproduction in any medium, provided the original work is properly cited.

\begin{abstract}
The purpose is to explore the influencing factors in English teaching under the new curriculum concept. Teachers and students in a representative middle school in a city are taken as the research object. First, classroom observations are employed to have a preliminary understanding of the teaching mode of English reading. Then, a questionnaire survey is conducted to analyze teachers' and students' opinions about English reading education. Besides, some interviews are given to the teachers and the students for deep study. Subsequently, the results of the survey are analyzed to summarize the factors that affect the effectiveness of English reading education under the new curriculum concept. The results show that the influencing factors of the teaching effect include teachers, students, and teaching materials. Finally, the corresponding strategies are put forward in response to the relevant problems, and they have a positive effect on promoting the English teaching research. The research content provides a reference for middle school English teaching, solves the problems in English teaching, and makes a contribution to improving teachers' teaching ability in the senior high school.
\end{abstract}

\section{Introduction}

After the New Curriculum Standard on Students' Education in China was issued, senior high school education made some progress and achieved development. With the continuous advancement of the new curriculum standard, the problems in senior high school teaching have gradually emerged, and English teaching is no exception [1]. Due to the further development of English education, English teaching becomes particularly important, which constitutes the main part of teaching in senior high school [2]. The purpose is to find out the problems in English teaching and then try to explore and discuss the subjective and objective factors that affect students' ability in English teaching with some experienced teachers, thereby putting forward some valuable opinions and suggestions on middle school English teaching from a new perspective.

The existing problems in English teaching are as follows. English class is still teacher-centered, and there is no definite teaching goal; students spend much time doing endless exercises to improve their scores temporarily; students' psychological development as well as students themselves is ignored by teachers [3]. There is no long-term effective feedback mechanism in class, and students only want to score higher by doing exercises, rather than out of interest; they cannot employ learning strategies flexibly and do not have good reading habits; the reading materials offered are not moderate, and they are boring for students $[4,5]$. According to the students' actual needs, teachers should help them develop good reading habits, pay attention to students' personality and psychological development, and strive to treat them as individuals and help each one achieve their full potential [6]. In addition, teachers should work in teams, and each team should be assigned a task. For example, one team is asked to hold teaching and research meetings; another collects and sorts reading materials, gradually forming a test database suitable for their students [7]. Middle school students in cities are more representative with uneven scores 
and receive more education than those in rural areas, and middle school English is the most basic, so it is convenient to study the factors that affect the English teaching effect under the new curriculum concept.

English teachers and students of a senior high school in a city are selected as the research objects, and the factors influencing English teaching are studied and analyzed. The methods involve a questionnaire and an interview, and the following three questions are put forward to realize the research purpose. The questions are as follows. (1) What is the current situation of high school English teaching? (2) What are the factors that affect high school English teaching? (3) What are the teaching strategies based on the factors? After the data are collected, sorted, and analyzed, the current situation of teaching is informed, the factors that affect English teaching are explored, and the corresponding suggestions to improve high school English teaching are discussed.

\section{English Teaching Design Based on New Curriculum Concept}

2.1. Research Issues. Years of teaching convinces us that there are some problems in senior high school English teaching. In recent years, China has issued and implemented the new curriculum standards, but the problems are not solved fundamentally [8]. The survey shows that students in English class have no interest in reading, and the major obstacles in doing exercises are narrow vocabulary, complicated grammar structures, and difficult contents, which make them flinch when the students have trouble in English learning, and the students' self-motivated language practice activities are rare [9]. In addition, some open classes also show that teachers tend to pay attention to students with good performance, neglecting the ones with poor basic knowledge of English. Therefore, the research content is as follows: the current situation of middle school English teaching is analyzed; the factors that affect middle school English teaching are explored; and the strategies that improve the effect of middle school English teaching are proposed.

2.2. Research Objects. The investigated objects are some students and teachers. 300 students from a middle school in a city are taken as the research object, and each class has 50 students. There are three types of classes in middle school, and they are rocket class, experimental class, and ordinary class. Before the experiment, two classes of each type are selected. Also, 20 English teachers in the third grade of senior high school are surveyed. According to the researchers, 30 is the minimum sample number, and it makes sense to have more than 30 samples; the number of the collected data that is less than 30 cannot form a normal distribution. The student's questionnaires are 300, while the number of teachers is less than 30. Therefore, teacher's English teaching survey is mainly conducted by interviews, supplemented by questionnaires. 320 students and English teachers are investigated, and 288 valid questionnaires are collected, with a percentage of $90 \%$.
2.3. Data Collection. The first step is to find the right questionnaire. According to the relevant principles of questionnaire preparation, the existing questionnaires are reviewed to determine the form of the questionnaire, and then the questionnaire is carefully prepared and designed by combining the actual situation of high school English teaching. The second is measurement. To ensure the effective recovery of the questionnaire, a survey is carried out in a representative senior high school. The face-to-face questionnaire is helpful for the respondents to understanding the problems in time and winning their cooperation. The third step is to sort out the test results. The collected questionnaires are carefully and strictly reviewed, and invalid questionnaires are eliminated to make the research effective and scientific [10]. English teachers should strengthen the learning of English teaching theories at home and abroad, combine classroom practice, change the traditional teaching mode, and fully mobilize the enthusiasm of students. The present situation of traditional grammar teaching method should be appropriately changed, the communicative method should be combined with the situational teaching method, and the teacher-centered absolute teaching mode should be changed into the student-centered new teaching mode to ensure the accuracy of data.

2.4. Classroom Observation. Classroom observations are undertaken, and the main tasks are observing student's vocabulary, their reading proficiency, and teachers' teaching strategies. The results show that teachers pay more attention to enlarging student's vocabulary and emphasize the spelling and meaning of the new words. In terms of students' mastery of word meanings, teachers usually make spot checks in the classroom and just play the role of supervision. Moreover, they do not pay enough attention to the connotations of vocabulary and seldom provide appropriate polysemy exercises to help students master the deep meaning of vocabulary and its less common usage in context. As for reading comprehension, teachers' discourse awareness is not strong enough to cultivate students' text sense effectively. Besides, the reading texts are rarely classified according to different topics, which is not conducive to improving students' reading efficiency. Students lack the communicative environment necessary to consolidate and internalize language knowledge. Students have few opportunities to use English outside the classroom. This is not only true in schools with good conditions for small classes but also worse in large classes with poor conditions. Students rely on very limited opportunities for classroom English communication. In addition, the students' cultural background knowledge reserve is seriously insufficient, and most of what they understand is the knowledge reflecting Chinese society and culture and the college life under this background.

\section{Data Analysis}

3.1. Analysis of the Results of the Survey on Teachers. The results of the survey on in-service teachers are shown in Figure 1. 


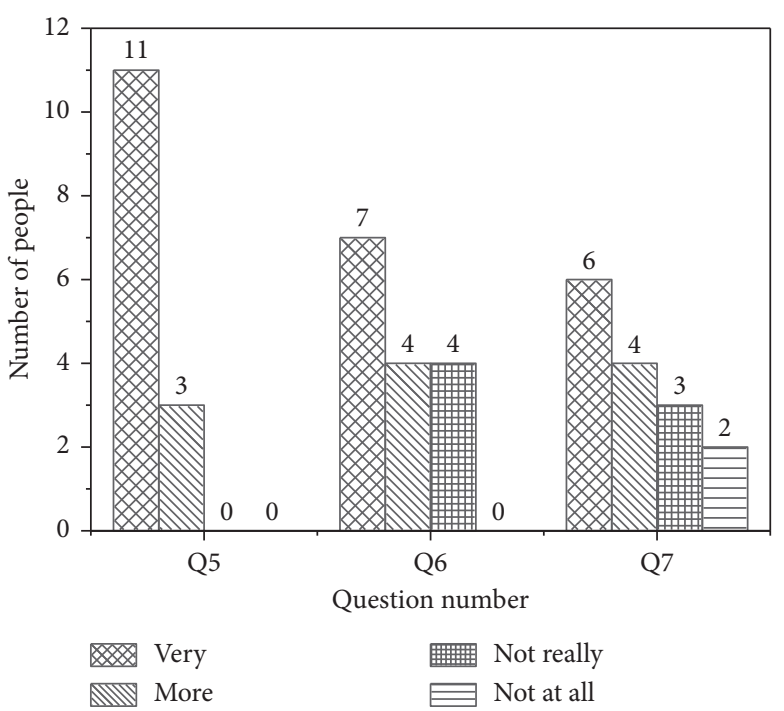

(a)

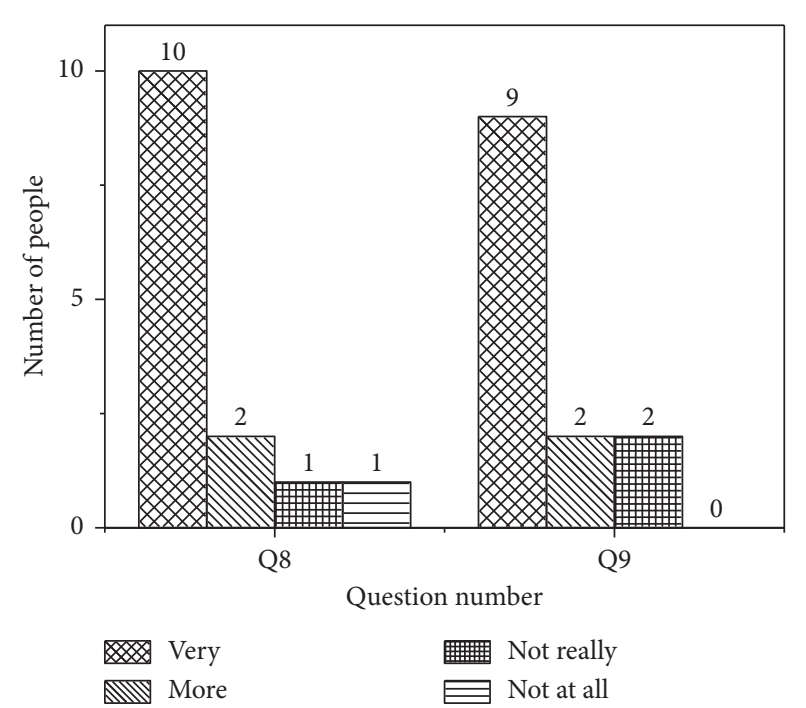

(b)

FIGURE 1: Survey results of teachers' teaching concepts. (a) Teachers' teaching strategies. (b) Teachers' teaching theories.

The survey on teacher's English teaching strategies shows that 11 teachers hold the idea that appropriate strategies can improve students' learning ability, while 7 teachers argue that the importance of learning should be focused on, rather than the strategies. Some teachers disagree to emphasize the importance of English teaching, and they assume that if the basic knowledge is developed, their performance will be improved naturally. Also, they think that the teaching theory has no practical use. In terms of teacher's English teaching theory, 10 teachers hold that they should often employ relevant teaching theories to guide students to read, and 9 teachers attach importance to nonverbal knowledge like cultural background.

The survey on teachers' requirements for students' exercise training is shown in Figure 2.

The survey on teachers' requirements for students' exercise training shows that 10 teachers think that the reading materials in class are limited and the students need to read more extracurricular materials as a supplement. About $40 \%$ of the teachers argue that there is no need for training on reading methods. In the interview, the teachers also expressed their concern that the reading task could not be completed in class, leading to some reading problems that cannot be solved by students themselves. Therefore, a lot of factors have to be taken into consideration in the implementation of the teaching plan.

The survey on teachers' attitude towards reading is shown in Figure 3.

The following can be inferred from Figure 3. Most teachers thought much concern should be given to the text structure analysis of reading materials, followed by teaching students' reading strategies. Half of the teachers assumed that the biggest problem is lack of reading materials. To make the research results more scientific and comprehensive, interviews are applied for more data.
3.2. Result Analysis of the Survey on Students. The results of the focus of the teaching content and question-answering skills are shown in Figure 4.

Figure 4(a) shows that in the process of teaching, vocabulary and phrases are the ones that teachers think about the most, followed by grammar. The skills and training of reading strategies receive little attention from the students. Only six students thought that teachers focused on cultural background in English teaching. Figure 4(b) indicates that the teachers give some guidance to the students' answering skills, which includes guessing the meaning of words according to the context, grasping the key sentences, and paying attention to the turning words. They are the three most commonly used in answering questions. It is noticed that only 19 students chose the option of "all of the above," which shows that the teachers give students reading strategy guidance in reading education, but the guidance is inadequate.

The interaction between teachers and students in teaching class and students' interest in English reading are shown in Figure 5.

In terms of the interaction in English class, $53 \%$ of the students hold that there is little interaction between teachers and students in reading education, $31 \%$ think that teachers occasionally interact with students, and only $14 \%$ think that teachers often interact with students. As for students' interest and attitude towards English reading, only 30 students are very interested in reading, accounting for only about $10 \%$. More than $20 \%$ of the students are interested in reading. However, more than $40 \%$ of the students are not interested in reading.

The attitude towards English learning and the students' learning motivation are shown in Figure 6.

As for the students' attitude towards English learning, 107 think that learning English is boring, and they 


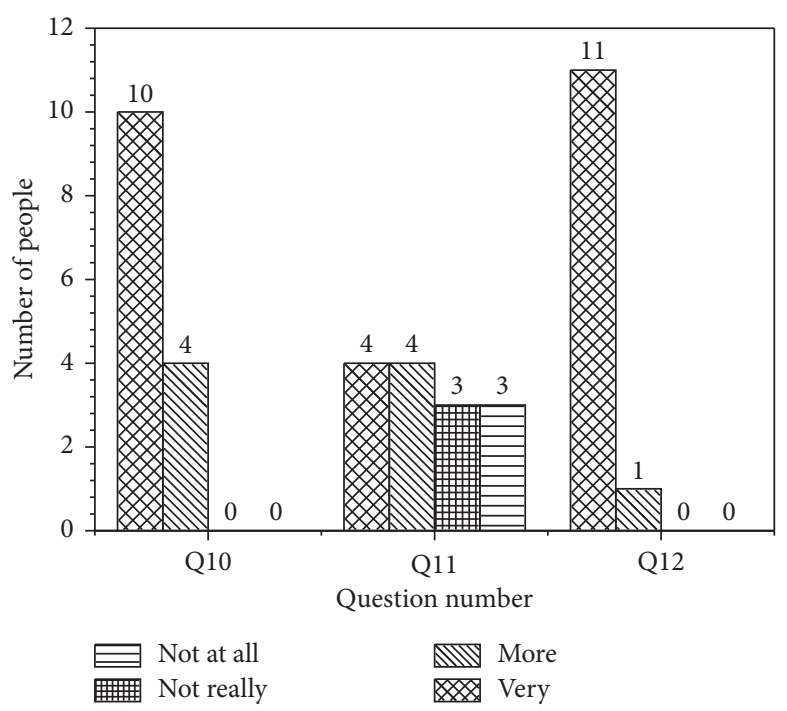

(a)

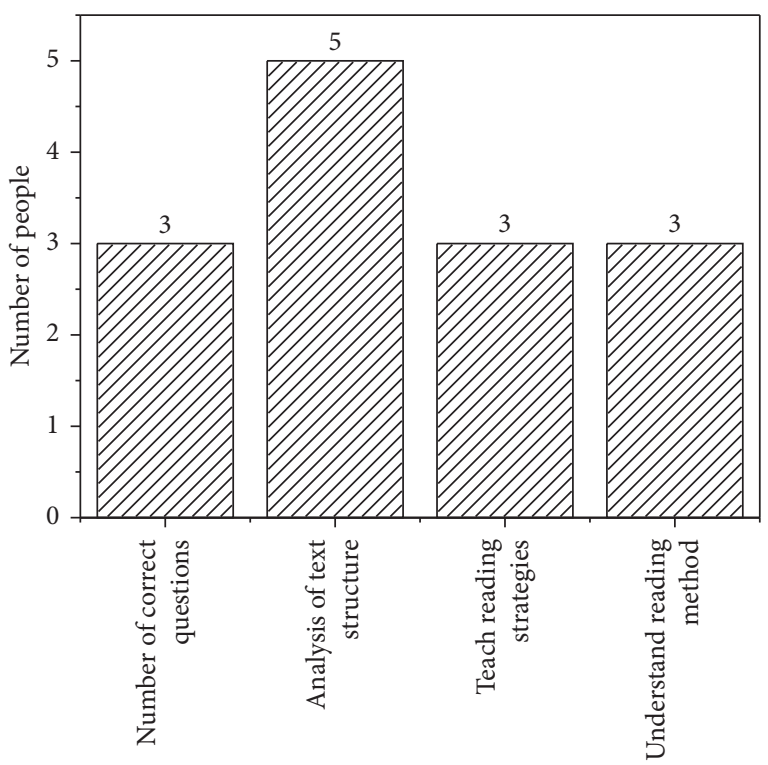

(b)

Figure 2: Teachers' requirements. (a) Teachers' English exercise requirements. (b) Teachers' attitude towards English teaching.

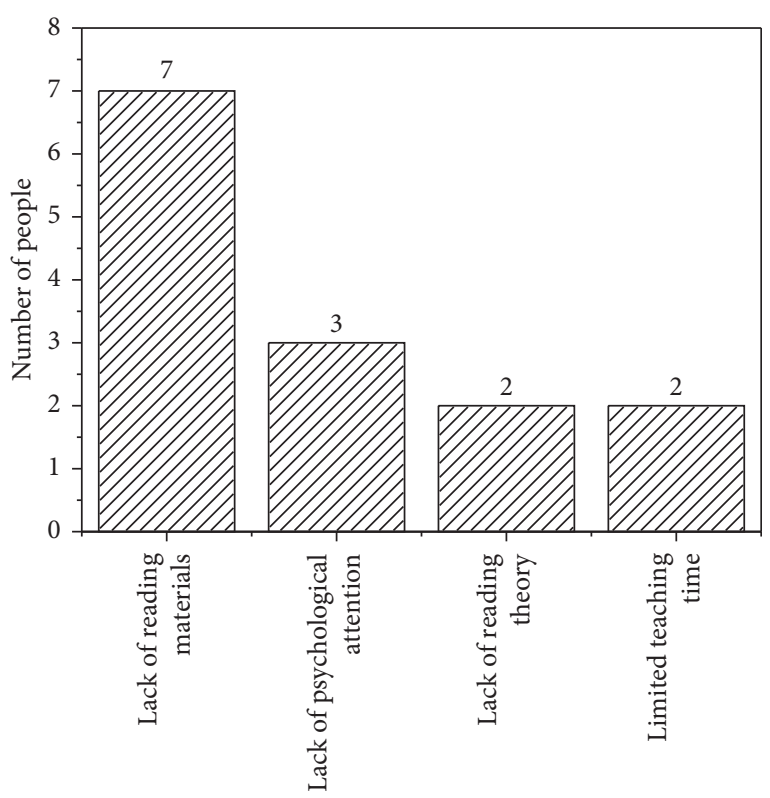

FIGURE 3: Results of teachers' attitude towards reading.

chose the option casually. 74 students did not finish answering the questions on the questionnaire. Only 34 students actively read, wanted to expand their knowledge, and did extra exercises for ability training. According to the results of the motivation for learning English, 160 students hope to improve their reading ability and test scores through practice, while only 26 students want to do exercises for the improvement of their reading ability, which is opposite to the original educational objective.

The results of the survey on students' habit and the obstacles in the learning process are shown in Figure 7.
About 13\% of the students chose "no such habit," and $23 \%$ read or read with the help of the moving nib. $34 \%$ said that they first translated the reading content into Chinese and then thought about the questions; $30 \%$ said that they repeated their reading back and forth in the process of reading without missing any words. The results of the survey on English learning obstacles prove that more than onethird of the students thought that they have narrow vocabulary and poor grammar knowledge, which are the biggest obstacles in English learning. The second option is "lack of effective reading strategies," and the option wins about $30 \%$ students; the third is "having no interest in reading," and about $18 \%$ students chose it. The fourth is "insufficient background knowledge," and it was chosen by $9 \%$ students. The last one is "having no interesting and easy to read materials," with a percentage of $7 \%$ students.

The results of the survey on the level of the difficulty of the reading materials and the number of English reading materials are shown in Figure 8.

The following can be inferred from Figure $8.35 \%$ of the students thought that most of the reading materials are too difficult, which reduced their confidence in continuing the reading; $52 \%$ argued that the level of the difficulty of reading materials is moderate and acceptable; $13 \%$ of the students thought that the reading materials are too simple to improve their ability. This proves that almost all the students are not satisfied with reading materials. $25 \%$ of the students assumed that the reading materials suitable for them are abundant; $32 \%$ said that they are little; $43 \%$ thought that it is difficult to find appropriate reading materials.

3.3. Influencing Factors and Strategies. In English teaching, the main factors that affect the teaching effect include teachers, students, and teaching materials. The influencing 


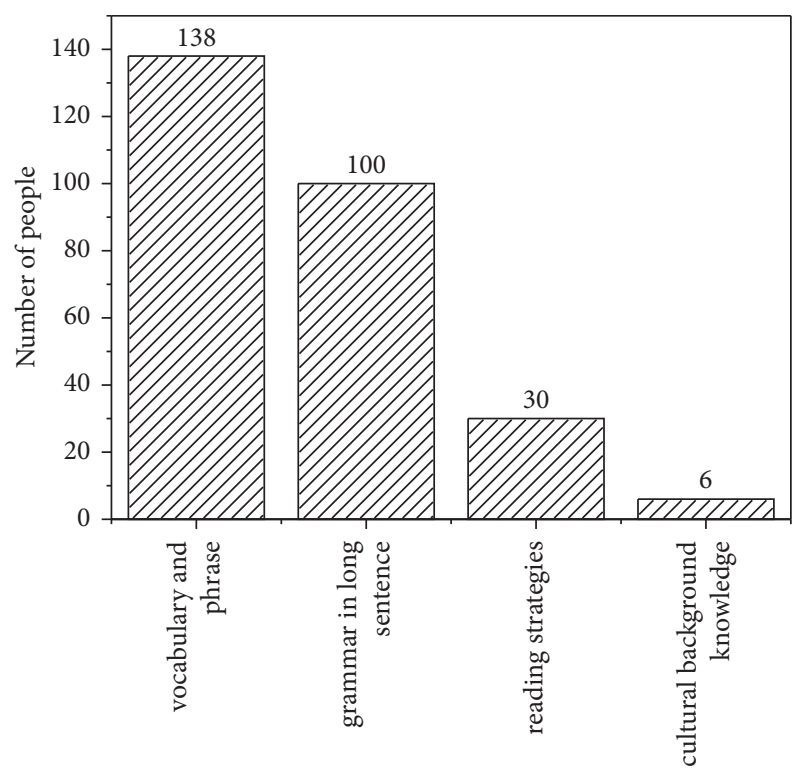

(a)

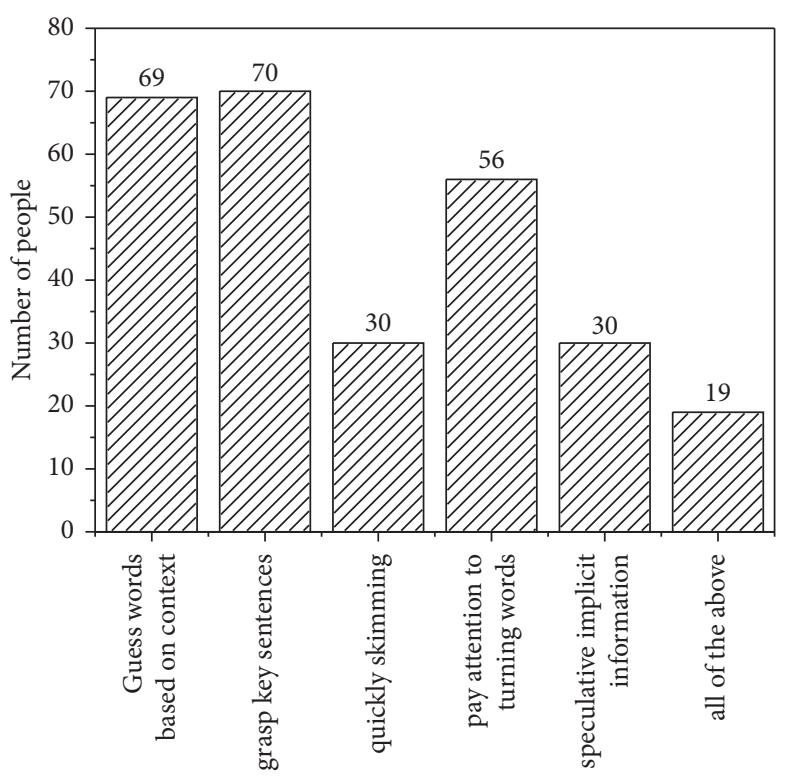

(b)

FIGURE 4: Results of the survey on teaching strategies. (a) The focus of teaching content. (b) Question-answering skills.

factors of teachers include three aspects. The first one refers to teachers' teaching ideas, which directly affect teaching methods, teaching focus, and teaching effect. If a teacher pays more attention to vocabulary and grammar, students emphasize them accordingly. The second one refers to teachers' achievements. A knowledgeable teacher with excellent English listening, speaking, reading, and writing ability can cultivate the talents of students as outstanding as he/she is, which has a positive impact on students. The last one refers to teaching strategies. In the process of English reading education, teachers should consciously introduce the corresponding reading skills and strategies, so that students can benefit a lot from English reading [11].

Three factors affect students' English teaching. The first one refers to students' reading motivation and attitude. Only when students have correct learning motivation and a positive attitude can teaching achieve the expected goal. This is mentioned in relevant literature $[12,13]$. The second one refers to reading ability and strategies. In the process of English reading, students should consciously learn and use certain reading skills and strategies, such as skimming, searching, guessing new words, reasoning, judging, predicting, and summarizing. These strategies greatly affect the effect of reading education, which is consistent with the literature $[14,15]$. The third one refers to personality and psychological factors. Students' psychological factors include anxiety, inhibition, empathy, classroom communication, and cross-cultural awareness, and teachers should have insight into students' personality and psychological activities and carry out targeted reading education [16].

The best materials come from textbooks. The arrangement and the level of difficulty of textbooks directly affect the teaching effect. Therefore, the textbook should be carefully designed and the content should be based on the syllabus, in which vocabulary and syntax knowledge are the foci of the college entrance examination [17]. It is very appropriate to use the content of the textbook as the reading materials because textbooks have a great influence on teaching and they are the key to the implementation of curriculum standards, the main basis for teachers to design and carry out teaching activities, and also the core content of students' learning. Reading materials in English textbooks account for a large proportion in each unit, and there are many language points [18]. The learning degree of the reading materials in English textbooks determines their English achievements. However, the reading materials are too few in the textbooks, and extracurricular reading materials need to be supplemented.

In view of these factors, the corresponding teaching strategies are put forward for teachers. Teachers should update their teaching concepts and apply them to the teaching practice, which can enhance teachers' sense of achievement and change their teaching strategies. The feasible teaching strategies are cultivating students' good reading habits, arousing their enthusiasm, and changing their attitude towards reading [19]. The teachers should also develop students' habit of thinking in English and the habit of reading with a time limit and increase the students' reading volume. Reading education should be based on students' personalities and psychology. With regard to the teaching materials and extracurricular reading materials, it is hoped that relevant foreign language research institutions should pay attention to the natural cohesion and difficulty in transition of senior high school teaching materials, so that teachers can select them according to students' learning progress [20]. 


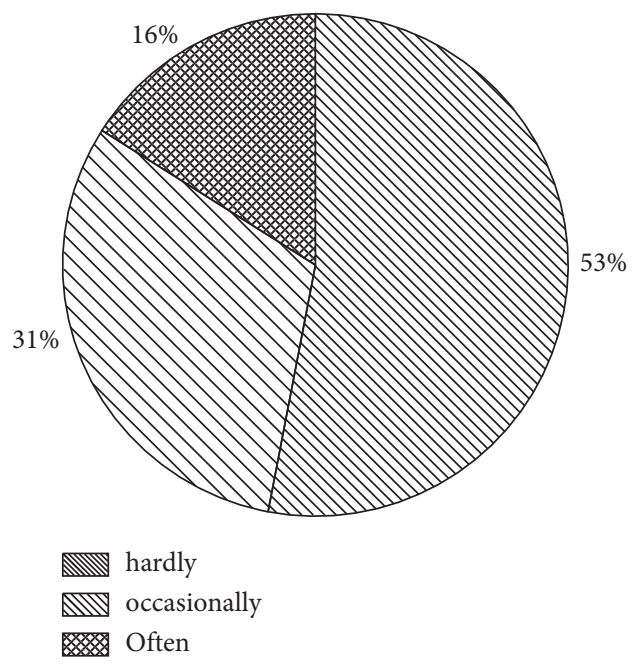

(a)

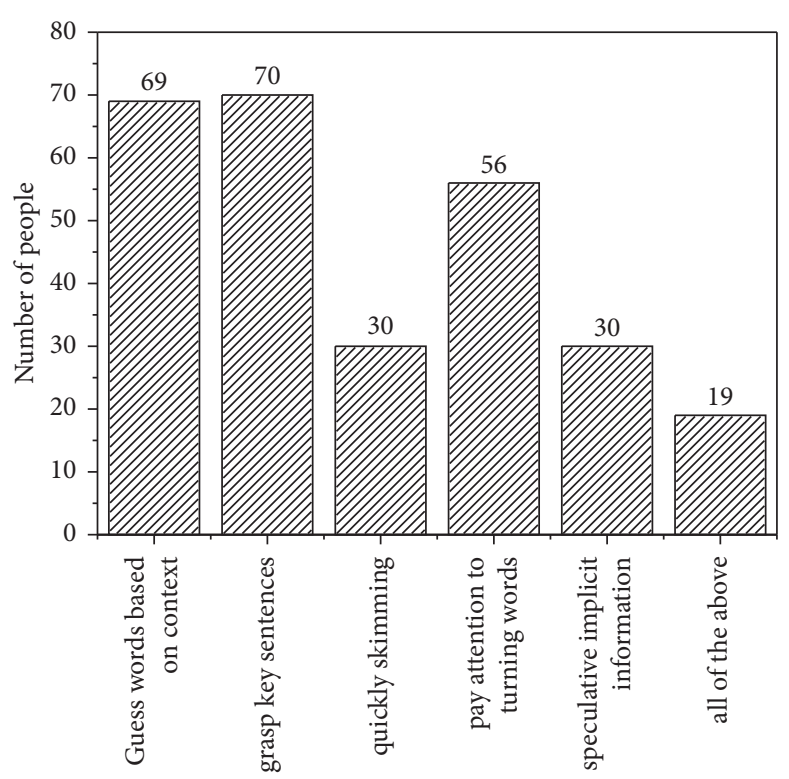

(b)

FIGURE 5: Interaction between teachers and students and students' interest in reading. (a) Frequency of teacher-student interaction. (b) Students' interest in reading.

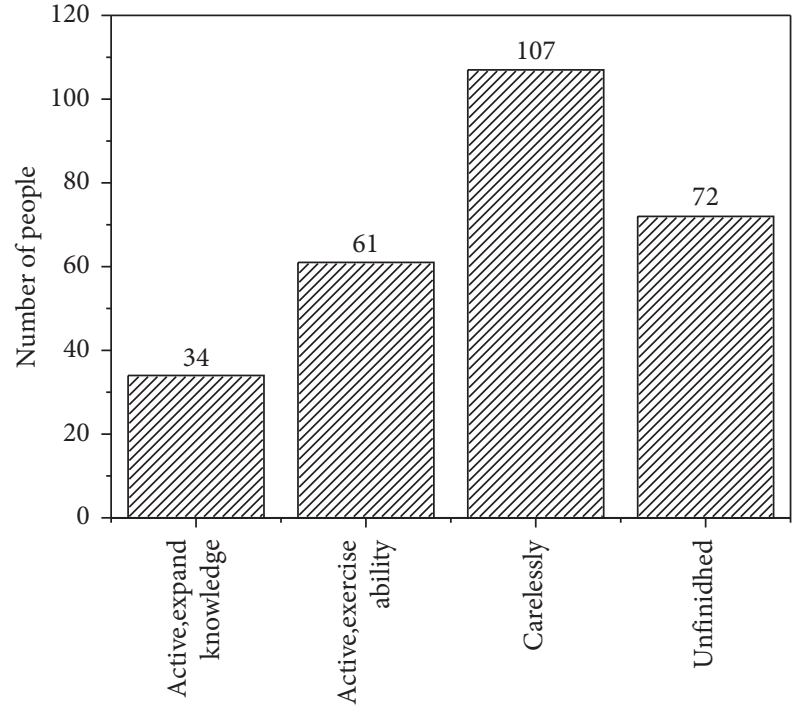

(a)

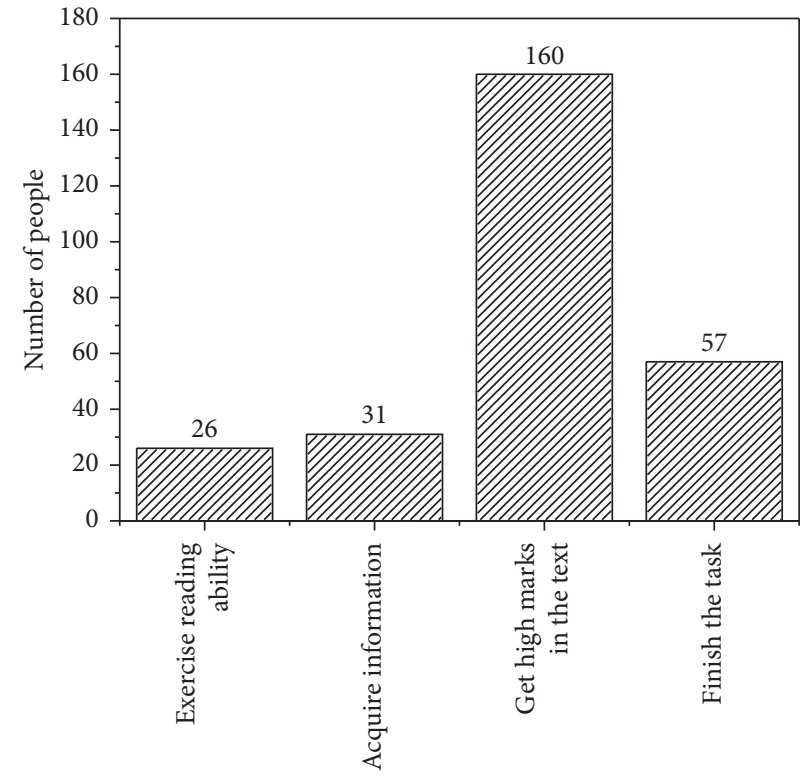

(b)

Figure 6: Attitude towards English learning and the students' learning motivation. (a) Attitude towards English learning. (b) Motivation of learning English.

\section{Discussion}

The results of the surveys show that English teachers in senior high schools are under the pressure of examination. Most of the English reading teaching modes are established to serve for the college entrance examination. In this case, English classes should be diversified and flexible to arouse students' interest in learning and improve their learning ability. It is found that half of the teachers usually require the students to complete the exercise on their workbooks and just check whether they complete the exercise or not, ignoring the correct probability. This shows that the effect of English teaching is affected by the heavy teaching loads, the teachers' limited time, and the lack of supervision and evaluation of English practice. Half of the teachers chose the English materials that are not only in line with the level of the difficulty and themes of the college entrance examination but also original. Other teachers chose the teaching materials 


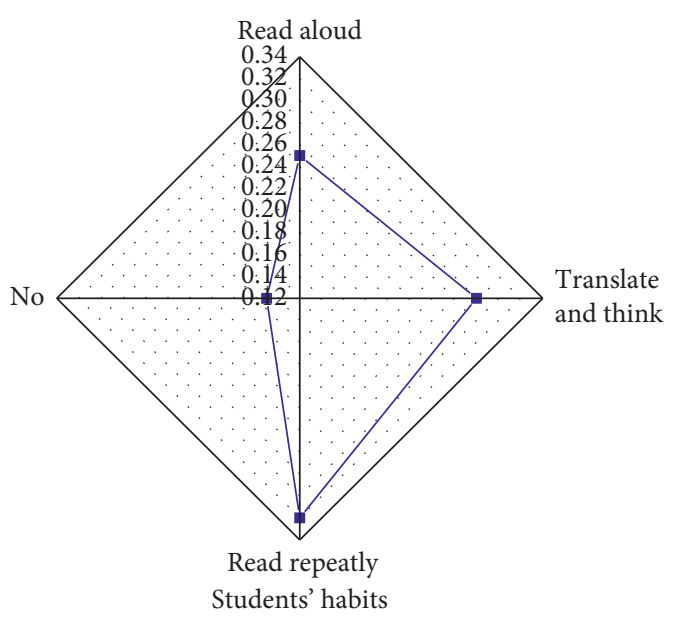

(a)

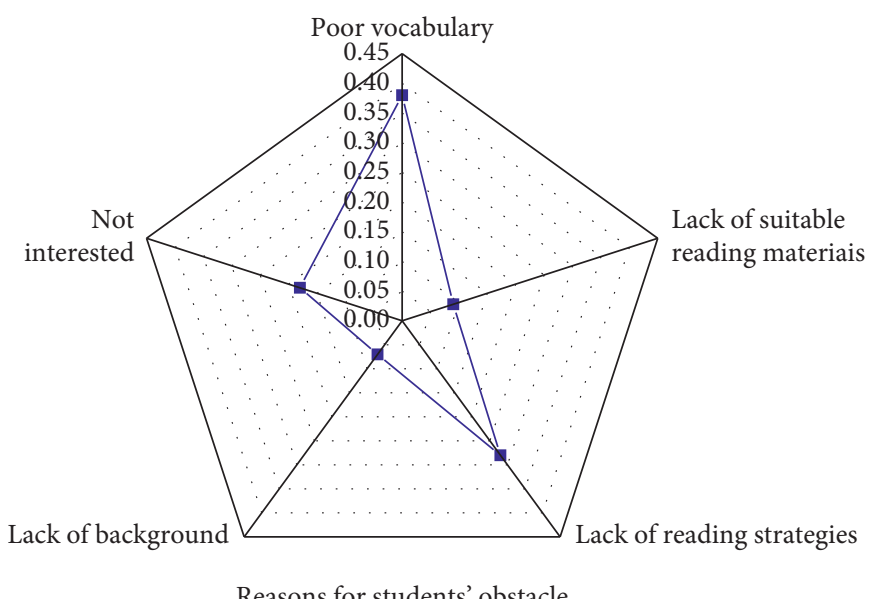

(b)

Figure 7: Habits and obstacles in learning English. (a) Habits in learning English. (b) Obstacles in learning English.

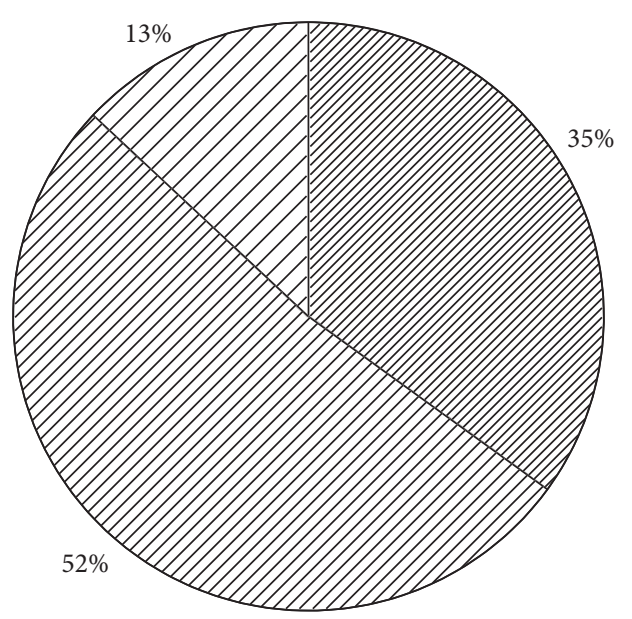

Difficulties of English textbooks

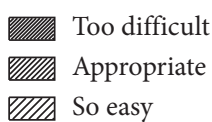

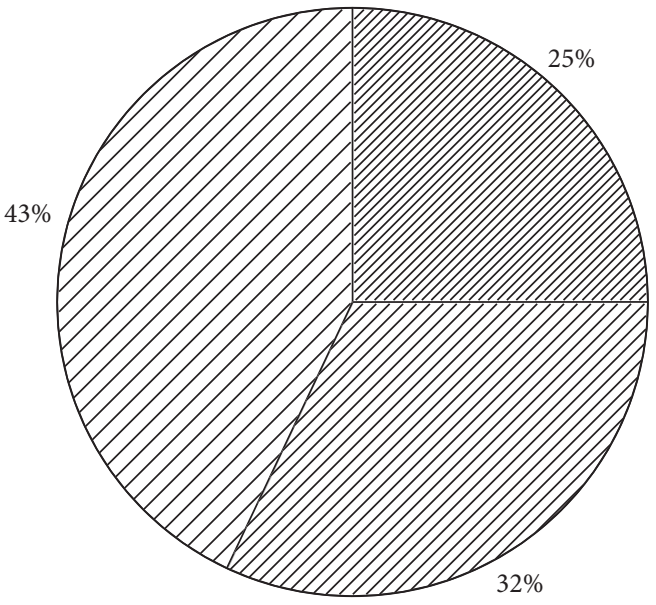

Appropriateness of English textbooks

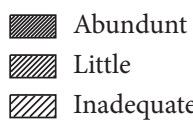

(a)

(b)

FIGURE 8: Reading materials and reading volume. (a) Difficulties of English textbooks. (b) Appropriateness of reading volume.

with rich background knowledge, novel ideas, and a sense of the times. Nearly two-thirds encourage the students to read 21st Century Teens, which is considered to be effective, interesting, and practical. Teachers tend to pick up the materials with rich content to make the students concentrate and stimulate their desire for reading. As a result, the primary basis for teachers to choose materials is whether they meet the requirements of the level of the difficulty and topics of the college entrance examination, and the second is whether the content is rich and the intention is novel, which is limited by the college entrance examination.

Concerning English reading under the new curriculum standard, teachers participating in the survey agree that English teaching becomes the main source of information and an important channel to acquire knowledge. In the new situation, it helps students to broaden their horizons and have access to more information timely, laying a solid foundation for the overall development of students' English learning ability. In teaching, teachers should guide the students to acquire knowledge and skills, develop their emotions, and have the correct attitude. Learning strategies and cultural awareness can help students develop their talents. Since teachers play a leading role in teaching, their teaching ideas and decisions directly affect reading education. In the classroom, although the guidance of teachers is very important to the teaching effect, the role of students cannot be ignored, and they also play an important role in the process of English teaching. 


\section{Conclusion}

Based on the investigation and study of the main problems in senior high school English reading education, both teachers' teaching and students' learning in English reading education have problems to be solved. Under the new curriculum concept, three factors affect the effectiveness of English classroom teaching: teachers, students, and teaching materials. According to the new curriculum standard, the current situation of the senior high school English teaching is investigated and it is found that there are many problems in English teaching, which should be improved. The corresponding teaching strategies are put forward to solve the relevant problems. This study has a positive effect on promoting English teaching under the new curriculum concept and provides a research direction for future English curriculum reform. It is expected that more scholars will conduct more comprehensive and in-depth research on English teaching, so that English teaching under the new curriculum standard will gradually become mature, realizing the perfect integration of English learning and practice.

\section{Data Availability}

No data were used to support this study.

\section{Conflicts of Interest}

The author declares that there are no conflicts of interest.

\section{References}

[1] N. Oeamoum and C. Sriwichai, "Problems and needs in English language teaching from the viewpoints of pre-service English teachers in Thailand," Asian Journal of Education and Training, vol. 6, no. 4, pp. 592-601, 2020.

[2] X. Wei, "Research on the development strategy of crosscultural ecological education in English translation teaching at colleges," Ekoloji, vol. 28, no. 107, pp. 1665-1669, 2019.

[3] S. C. Chien, "Writing for scholarly publication in English for Taiwanese researchers in the field of English teaching," Sage Open, vol. 9, no. 3, Article ID 2158244019870187, 2019.

[4] Y. Du, "Discussion on flipped classroom teaching mode in college English teaching," English Language Teaching, vol. 11, no. 11, pp. 92-97, 2018.

[5] U. Sulistiyo, "Factors affecting English language learning in English as a foreign language (EFL) context: a literature review study," IJER (Indonesian Journal of Educational Research), vol. 3, no. 1, pp. 20-24, 2018.

[6] F. Huang, T. Teo, and M. Zhou, "Factors affecting Chinese English as a foreign language teachers' technology acceptance: a qualitative study," Journal of Educational Computing Research, vol. 57, no. 1, pp. 83-105, 2019.

[7] M. M. Rahman, A. Pandian, and M. Kaur, "Factors affecting teachers' implementation of communicative language teaching curriculum in secondary schools in Bangladesh," Qualitative Report, vol. 23, no. 5, pp. 1104-1126, 2018.

[8] Y. You, “The seeming 'round trip' of learner-centred education: a 'best practice' derived from China's New Curriculum Reform," Comparative Education, vol. 55, no. 1, pp. 97-115, 2019.
[9] A. M. Songbatumis, "Challenges in teaching English faced by English teachers at MTsN Taliwang, Indonesia," Journal of foreign language teaching and learning, vol. 2, no. 2, pp. 54-67, 2017.

[10] M. Geuens and P. De Pelsmacker, "Planning and conducting experimental advertising research and questionnaire design," Journal of Advertising, vol. 46, no. 1, pp. 83-100, 2017.

[11] M. Mohammadi and A. Amini Faskhodi, "Modeling AMO factors affecting English teachers' performance using system dynamics," Language Teaching Research Quarterly, vol. 16, pp. 22-39, 2020.

[12] K. Andi and B. Arafah, "Using needs analysis to develop English teaching materials in initial speaking skills for Indonesian college students of English," The Turkish Online Journal of Design, Art and Communication (TOJDAC), pp. 419-436, Special Edition, 2017.

[13] T. Teo, M. Zhou, A. C. W. Fan, and F. Huang, "Factors that influence university students' intention to use Moodle: a study in Macau," Educational Technology Research \& Development, vol. 67, no. 3, pp. 749-766, 2019.

[14] M. J. Nelson, R. Voithofer, and S.-L. Cheng, "Mediating factors that influence the technology integration practices of teacher educators," Computers \& Education, vol. 128, pp. 330-344, 2019.

[15] M. Abrar, A. Mukminin, A. Habibi, and A. Fadhil, "If our English isn't a language, what is it?" Indonesian EFL Student Teachers' Challenges Speaking English," Qualitative Report, vol. 23, no. 1, pp. 129-145, 2018.

[16] S. Wang and S. Seepho, "Facilitating Chinese efl learners' critical thinking skills: the contributions of teaching strategies," Sage Open, vol. 7, no. 3, pp. 2158244017734024-2158244017734031, 2017.

[17] P. A. Jennings, J. L. Brown, J. L. Frank, and B. Joshua, "Impacts of the CARE for Teachers program on teachers' social and emotional competence and classroom interactions," Journal of Educational Psychology, vol. 109, no. 7, Article ID 1010, 2017.

[18] O. Sert, "Transforming CA findings into future L2 teaching practices: challenges and prospects for teacher education," Classroom-based Conversation Analytic Research: Theoretical and Applied Perspectives on Pedagogy, Springer, Sweden, pp. 259-279, 2021.

[19] M. Gamboa Á, "Reading comprehension in an English as a foreign language setting: teaching strategies for sixth graders based on the interactive model of reading," Folio, vol. 45, pp. 159-175, 2017.

[20] X. Wei, "Optimization design of teaching strategies for English teaching achievement improvement based on original algorithm," Wireless Personal Communications, vol. 102, no. 2, pp. 1191-1201, 2018. 